\title{
Agricultural labor productivity and sustainable development impacts and indicators
}

\author{
Hamideh Zehtab* and Hayk Ghazaryan
}

College of Economics and Management of the Economy, National Agrarian University of Armenia, Yerevan, Armenia

\begin{tabular}{|c|c|}
\hline CHRON I C L E & ABSTRACT \\
\hline $\begin{array}{l}\text { Article history: } \\
\text { Received January 20, } 2015 \\
\text { Received in revised format } 28 \\
\text { February } 2015 \\
\text { Accepted 22 April } 2015 \\
\text { Available online } \\
\text { April } 272015 \\
\text { Keywords: } \\
\text { The agricultural Jahad } \\
\text { organization } \\
\text { Employee efficiency } \\
\text { Organizational structure }\end{array}$ & $\begin{array}{l}\text { The agricultural Jahad organization of Khorasan and Razavi province is one of Iran's biggest } \\
\text { agricultural firms, which is responsible in agricultural sector of the province. During the past } \\
\text { few years, there has been a growth in organization's responsibilities and the number of } \\
\text { employees has increased. This paper presents an empirical investigation to determine different } \\
\text { methods for increasing employees' efficiency. The study designs a questionnaire in Likert } \\
\text { scale consists of } 20 \text { questions, distributes it among } 127 \text { randomly selected employees who } \\
\text { worked for this organization. Cronbach alphas for all components of the survey were calculated } \\
\text { well above } 0.70 \text {, which validate the overall questionnaire and Kolmogorov-Smirnov test has } \\
\text { indicated that the data were normally distributed. Using t-student test, the study has confirmed } \\
\text { three approaches for increasing efficiency including methods to improve employee } \\
\text { management and organizational structures, methods to improve financial and moral } \\
\text { encouragement system and methods for improvement of staff performance efficiency } \\
\text { assessment. }\end{array}$ \\
\hline
\end{tabular}

\section{Introduction}

Nowadays, one of the primary key issues for economic development is to build an organization with efficient workers (Lucas, 1998). In fact, human resources are considered as decisive component of any organization. Staff management is a measure for managerial principles over behavior, activity, methods, means and forms, for the purpose of efficient utilization of resources. In developed countries, there are different techniques for solving the key issues of staff management. However, general tendencies are to prepare a good staff selection procedure, the development of logical criteria for performance measurement, a comprehensive analysis to determine all employee requirements, employee promotion, increasing creativity and innovation among employees, etc. The management efficiency is a component of production efficiency, therefore special attention needs to be devoted to the improvement of efficiency for the whole process of strategy development and implementation of economic entities.

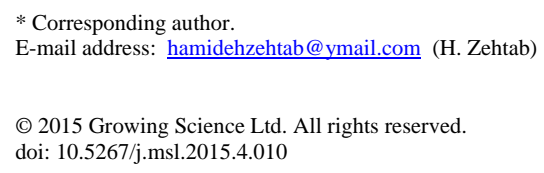


According to Al Mamun et al. (2015), for countries with substantial labor force such as China, Bangladesh, India, Pakistan etc. any long-run growth strategy has to concentrate on augmenting the domestic labor productivity. The emergence of globalization and factor mobility have given a guideline to gain from labor abundance for most of the labor plentiful countries by strategically converting plentiful labor into capital. Nevertheless, remittance inflow could lead to counterproductive strategy for growth, if it were viewed within the work-leisure framework. Al Mamun et al. (2015) recommended that though remittance had a positive effect on domestic labor productivity for countries with higher size of remittance inflow and plentiful labor force.

The Internet has different economic functions and is a basic part of the most economic activities and transactions. Najarzadeh et al. (2014) implemented a technique to investigate the effect of the Internet on labor productivity using data from 108 countries over the period 1995-2010. They reported that the Internet had positive and statistically significant impacts on labor productivity. Assuming other factors remain constant, increasing the number of Internet users by one percent could lead to an increase GDP per employed person by \$8.16-14.6. In addition, educational costs as a percentage of growth national income, per capita health expenditures, trade and gross capital formation as a percentage of GDP also maintained positive and statistically significant effects on labor productivity.

The existence of labor with high productivity at each stage of a project's development plays essential role in project success. Nasirzadeh and Nojedehi (2013) presented a system dynamics (SD)-based technique to model labor productivity. The complex inter-related structure of various factors influencing on labor productivity was modeled according to SD approach and the qualitative model of labor productivity was built using governing cause-and-effect feedback loops. They reported tha the labor productivity could be improved by implementation of proper solutions. Avikal et al. (2013) presented a mathematical technique for improvement of productivity.

Addessi (2014) investigated the impact of permanent and temporary labor contracts on both laboraugmenting and total factor productivity (TFP) using a panel dataset of Italian manufacturing companies. The study applied a structural approach in which company TFP followed a controlled Markov process influencing by the relative implementation of labor contracts, and labor services were perfect substitutes but with various labor-augmenting factors. The results of their survey indicated that when including labor-contract composition in the TFP process: i) the difference between permanent and temporary contracts in the labor-augmenting productivity factor was not substantial and ii) the incidence of permanent contracts in total contracts had a positive impact on TFP dynamics.

The standard analysis of the effect of employment protection legislation (EPL) on labour market outcomes focuses primarily on unemployment and job flows, disregarding possible effects on labour productivity. Lisi (2013) analyzed how the presence of a stringent protection legislation could influence on labour market in an equilibrium matching model with endogenous job destruction. They reported that high firing expenses partially could substitute high labour productivity in reducing job destruction and this, consequently, reduces the optimal level of productivity. In addition, the effect of EPL on unemployment was ambiguous but numerical exercises indicated unambiguously how higher firing restrictions could reduce various measures of aggregate welfare.

Many economists verify the fact that, the position of economic development for each country is a consequence of country's efficient employees and physical and financial resources are considered as the secondary issues. The role of employee in Iran's agricultural sector, as one of the most essential components of country's economy, has always been considered as the focus of experts and professionals. One of the active agricultural regions in Iran is located in the Khorasan Razavi province, which is provided with potential opportunities for agricultural development. The main responsibilities of this organization are summarized in 6 groups as follows, 
1) Policy making,

2) Research and development,

3) Works for supporting employees and farmers,

4) Works associated with crop sowing, animal breeding and aquatic animal issues,

5) Works associated with natural resources and investigation of water resources,

6) Rural key issues and development work.

During the past few years, there were 412 employees who were working in this organization in different divisions of the organization. However, recently, the number of workers have been increased because of expansion plans within the organization. The context of this research is to study ways to increase the efficiency of personnel management and conceptual approaches to problem solving have been observed weaknesses.

\section{The proposed study}

The agricultural Jahad organization of Khorasan and Razavi province is one of Iran's biggest agricultural firms, which is responsible in agricultural sector of the province. During the past few years, there has been a growth in organization's responsibilities and the number of employees has increased from 412 to nearly 800 people. This paper presents an empirical investigation to determine different methods for increasing employees' efficiency. The study designs a questionnaire in Likert scale consists of 20 questions, distributes it among some randomly selected employees who worked for this organization. The sample size is calculated as follows,

$$
n=\frac{N \times z_{\alpha / 2}^{2} \times p \times q}{\varepsilon^{2} \times(N-1)+z_{\alpha / 2}^{2} \times p \times q},
$$

where $N$ is the population size, $p=1-q$ represents the yes/no categories, $z_{\alpha / 2}$ is CDF of normal distribution and finally $\varepsilon$ is the error term. Since we have $p=0.5, z_{\alpha / 2}=1.96$ and $N=800$, the number of sample size is calculated as $n=140$. The study distributes 140 questionnaires and manages to collect 127 properly filled ones. Fig. 1 demonstrates personal characteristics of the participants.

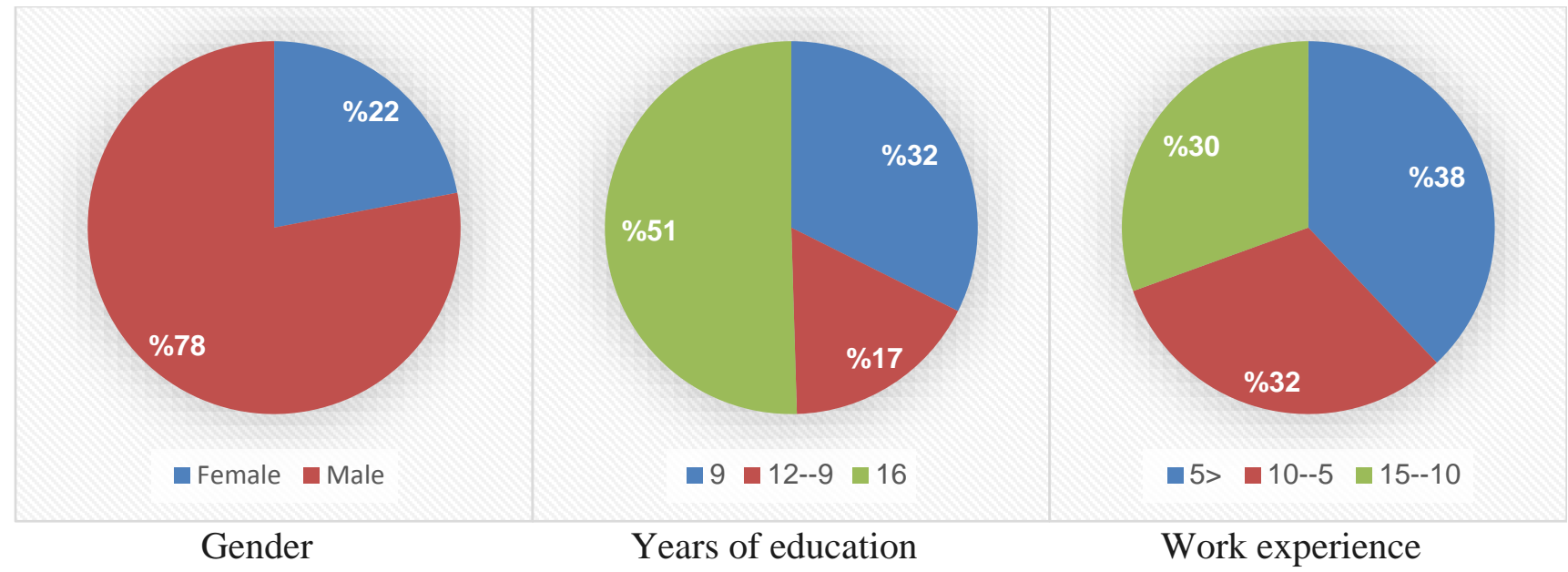

Fig. 2. Personal characteristics of the participants

As we can observe from the results of Fig. 1, most participants were male and nearly half of them had virtually no university education. In addition, $70 \%$ of the participants had less than 10 years of job experiences. Moreover, in the term of organizational responsibility, the $45.7 \%$ of participants were 
administrative staff and $81 \%$ of them were worker and administrative staff. The rest of respondents were enrolled in research and development (11\%), Human Resource department staff and vicepresidents (4.7\%) and top management (2.4\%).

The questionnaire consists of three parts as follows,

- Ways to improve staff management and organizational structures

- Ways to improve financial and moral encouragement system and

- Improvement of staff performance efficiency assessment methods

The questionnaire was first presented to some experts and they validated the overall questionnaire and then it was distributed among 5 selected people and Cronbach alphas for the above categories have been calculated as $0.979,0.990$ and 0.968 , respectively, which confirm the overall questionnaire. In addition, Kolmogorov-Smirnov test has indicated that the data were normally distributed.

\section{The results}

In this section, we present details of the implementation of the survey using t-student test.

\subsection{Staff management and organizational structures}

The first part of the survey is associated with ways to improve staff management and organizational structure, which consists of five components including Decentralization, Role of R\&D, Period of measurement, Firm size and Export status. Table 1 demonstrates the results of our survey.

\section{Table 1}

The summary of examining the methods for improvement of employee management and organizational structure

\begin{tabular}{lcccccc}
\hline \multirow{1}{*}{ Factor } & $\mathrm{t}$ & $\mathrm{df}$ & $\begin{array}{c}\text { Sig. } \\
\text { (2-tailed) }\end{array}$ & $\begin{array}{c}\text { Mean } \\
\text { Difference }\end{array}$ & $\begin{array}{c}\text { 95\% Confidence Interval } \\
\text { of the Difference }\end{array}$ \\
\cline { 2 - 7 } & & & & & Lower & Upper \\
\hline $\begin{array}{l}\text { Decentralization } \\
\text { Role of R\&D }\end{array}$ & 24.323 & 126 & .000 & 2.75591 & 2.5317 & 2.9801 \\
$\begin{array}{l}\text { Period of } \\
\text { measurement }\end{array}$ & 26.757 & 126 & .000 & 2.89764 & 2.6833 & 3.1120 \\
$\begin{array}{l}\text { Firm size } \\
\text { Export status }\end{array}$ & 28.478 & 126 & .000 & 2.30709 & 2.1468 & 2.4674 \\
\hline
\end{tabular}

According to the results of Table 1, all five components of the survey are statistically significant. In addition, the implementation of the Freedman test indicates that export plays the most important role followed by firm size and research and development.

\subsection{Financial and moral encouragement system}

The second hypothesis of the survey investigates the effects of different methods for improvement of financial and moral encouragement system. By an extensive investigation, a set of six essential factors connected with promotional system has been determined including job security, training program, income (salary and wage), reward based on PRP, staff commitment and encourage staff to creativity and innovation. These factors have been analyze to find out the relationships between these factors and 
raising employee productivity in Agricultural central organization of Khorasan Razavi. Table 2 presents the results of t-student test on these factors.

Table 2

The summary of the effects of six factors influencing on financial and moral encouragement system

\begin{tabular}{|c|c|c|c|c|c|c|}
\hline \multirow{3}{*}{ Factor } & \multicolumn{6}{|c|}{ Test Value $=3$} \\
\hline & \multirow[t]{2}{*}{$\mathrm{t}$} & \multirow[t]{2}{*}{ df } & \multirow[t]{2}{*}{ Sig. (2-tailed) } & \multirow[t]{2}{*}{$\begin{array}{c}\text { Mean } \\
\text { Difference }\end{array}$} & \multicolumn{2}{|c|}{$\begin{array}{c}\text { 95\% Confidence Interval } \\
\text { of the Difference }\end{array}$} \\
\hline & & & & & Lower & Upper \\
\hline Job security & 29.194 & 126 & .000 & 2.72441 & 2.5397 & 2.9091 \\
\hline Training and education & 29.324 & 126 & .000 & 2.83465 & 2.6433 & 3.0259 \\
\hline Income & 29.623 & 126 & .000 & 2.85039 & 2.6600 & 3.0408 \\
\hline Reward & 27.533 & 126 & .000 & 2.59843 & 2.4117 & 2.7852 \\
\hline Commitment & 25.940 & 126 & .000 & 2.66142 & 2.4584 & 2.8645 \\
\hline Creativity \& innovation & 31.476 & 126 & .000 & 2.64567 & 2.4793 & 2.8120 \\
\hline
\end{tabular}

According to the results of Table 2, all six components are statistically significant and we can, therefore, confirm the second hypothesis of the survey. In addition, the implementation of the Freedman test has indicated that income was the most important factor followed by training and education and job security.

\subsection{Improvement of staff performance efficiency assessment methods}

Finally, the last hypothesis of the survey is associated with the effects of various factors influencing on the improvement of staff performance efficiency assessment methods. Table 3 presents the results of our investigation.

\section{Table 3}

The summary of examining the effects of improvement of staff performance efficiency assessment methods

\begin{tabular}{|c|c|c|c|c|c|c|}
\hline \multirow{3}{*}{ Factor } & \multicolumn{6}{|c|}{ Test Value $=3$} \\
\hline & \multirow[t]{2}{*}{$\mathrm{t}$} & \multirow[t]{2}{*}{$\mathrm{df}$} & \multirow[t]{2}{*}{ Sig. (2-tailed) } & \multirow{2}{*}{$\begin{array}{c}\text { Mean } \\
\text { Difference }\end{array}$} & \multicolumn{2}{|c|}{$\begin{array}{l}\text { 95\% Confidence Interval } \\
\text { of the Difference }\end{array}$} \\
\hline & & & & & Lower & Upper \\
\hline Using IT system & 29.630 & 126 & .000 & 2.68504 & 2.5057 & 2.8644 \\
\hline Management-employee relations & 31.416 & 126 & .000 & 2.81890 & 2.6413 & 2.9965 \\
\hline Organizational culture & 46.828 & 126 & .000 & 3.46457 & 3.3182 & 3.6110 \\
\hline Communication \& cooperation & 39.128 & 126 & .000 & 3.49606 & 3.3192 & 3.6729 \\
\hline Working hour & 33.919 & 126 & .000 & 3.11811 & 2.9362 & 3.3000 \\
\hline
\end{tabular}

As we can observe from the results of Table 3, there were five factors determined for increasing labor productivity and our participants have confirmed the positive effects of these five factors on the performance improvement. Moreover, the implementation of the Freedman test has indicated that communication and cooperation was the most important factor followed by organizational culture and working labor.

\section{Conclusion}

In this paper, we have presented an empirical investigation to study the effects of three factors; namely "Ways to improve staff management and organizational structures", "Ways to improve financial and moral encouragement system" and "Improvement of staff performance efficiency assessment methods" for productively improvement in an agricultural organization in Iran. Using a questionnaire based survey, the study has confirmed the positive effects of these factors on productivity improvement. The 
results of this survey are somewhat consistent with other studies accomplished in the literature. For instance, Dorward (2013) investigated agricultural labour productivity, food prices and sustainable development impacts and indicators and argued that fundamental effects of links between agricultural productivity sustainability and real food price changes were often overlooked in current policy analysis.

\section{Acknowledgement}

The authors would like to thank the anonymous referees for constructive comments on earlier version of this paper.

\section{References}

Addessi, W. (2014). The productivity effect of permanent and temporary labor contracts in the Italian manufacturing sector. Economic Modelling, 36, 666-672.

Avikal, S., Jain, R., Mishra, P. K., \& Yadav, H. C. (2013). A heuristic approach for U-shaped assembly line balancing to improve labor productivity. Computers \& Industrial Engineering, 64(4), 895-901.

Dorward, A. (2013). Agricultural labour productivity, food prices and sustainable development impacts and indicators. Food Policy, 39, 40-50.

Lisi, D. (2013). The impact of employment protection legislation on labour productivity in a general equilibrium matching model. Cuadernos de Economía, 36(102), 128-141.

Lucas, R. E. (1998). On the mechanics of economic development. Econometric Society Monographs, 29, 61-70.

Al Mamun, M., Sohag, K., Uddin, G. S., \& Shahbaz, M. (2015). Remittance and domestic labor productivity: evidence from remittance recipient countries. Economic Modelling, 47, 207-218.

Najarzadeh, R., Rahimzadeh, F., \& Reed, M. (2014). Does the Internet increase labor productivity? Evidence from a cross-country dynamic panel. Journal of Policy Modeling, 36(6), 986-993.

Nasirzadeh, F., \& Nojedehi, P. (2013). Dynamic modeling of labor productivity in construction projects. International Journal of Project Management, 31(6), 903-911. 